\title{
Histamine 2 receptor antagonists do not improve the outcomes of hospitalized COVID-19 patients
}

\author{
Waseem Amjad ${ }^{1}$, Faisal Kamal ${ }^{2}$, Adnan Malik ${ }^{3}$, Ritu Singh ${ }^{4,5}$, Sultan Mahmood ${ }^{6}$ \\ ${ }^{1}$ Department of Internal Medicine, Albany Medical Center, Albany, NY, USA \\ 2Department of Gastroenterology, University of Tennessee, Memphis, TN, USA \\ ${ }^{3}$ Department of Internal Medicine, Loyola University Medical Center, Chicago, IL, USA \\ ${ }^{4}$ Department of Internal Medicine, University of Indiana, Fort Wayne, IN, USA \\ 5Johns Hopkins Bloomberg School of Public Health, Baltimore, MD, USA \\ ${ }^{6}$ Department of Gastroenterology, University at Buffalo, Buffalo, NY, USA
}

Gastroenterology Rev 2022; 17 (2): 146-151

DOI: https://doi.org/10.5114/pg.2021.107799

Key words: coronavirus disease 2019, H2 receptor blocker, proton pump inhibitors.

Address for correspondence: Waseem Amjad MD, Department of Internal Medicine, Albany Medical Center, Albany, NY, USA, phone: +1 9292457724, e-mail: waseemonline001@gmail.com

\begin{abstract}
Introduction: Some observational studies have demonstrated the benefit of famotidine in COVID-19-infected individuals. The preference of using an $\mathrm{H}_{2}$ receptor antagonist $\left(\mathrm{H}_{2} \mathrm{RA}\right)$ over proton pump inhibitors (PPI) during the COVID-19 pandemic has been questioned by clinicians.

Aim: To compare the outcomes of hospitalized patients who were taking $\mathrm{H}_{2} \mathrm{RA}$ vs. PPI.

Material and methods: We conducted a retrospective review of patients admitted for COVID-19 infection from 1 March until 31 July 2020. We included 396 patients admitted during the study period. Of the total, 39 (9.8\%) received $\mathrm{H}_{2} \mathrm{RA}$ and 86 (21.7\%) were taking PPI as home medications; 6 patients were taking both $\mathrm{H}_{2} \mathrm{RA}$ and PPI.

Results: The baseline characteristics and comorbid conditions were similar in both groups. The mean age was $57.79 \pm 17.36$ years, $43.2 \%$ were female, and $48.7 \%$ were Caucasian. The common comorbid conditions included HTN (56.8\%), obesity (44.4\%), diabetes mellitus (38.6\%), and coronary artery disease (30.1\%). Smoking was more prevalent in the PPI group (42.5\% vs. $18.2 \%$, $p=0.03)$. Gastrointestinal symptoms were seen on initial presentation in $31.1 \%$, and $43.9 \%$ had elevated liver enzymes. The $\mathrm{H}_{2} \mathrm{RA}$ group had similar mortality $(\mathrm{HR}=0.84,95 \% \mathrm{Cl}: 0.35-2.05)$ to the non- $\mathrm{H}_{2} \mathrm{~B}$ group. It remained non-significant as compared to PPI (HR = 0.34-3.19, 95\% Cl: 0.34-3.19). The secondary outcomes including readmission, ICU admission, and severe COVID infections (including ARDS and thromboembolism) were similar in these groups.

Conclusions: The $\mathrm{H}_{2}$ receptor antagonist used as a home medication did not show benefit over the PPI in patients admitted for COVID-19 infections.
\end{abstract}

\section{Introduction}

Globally Corona virus disease 2019 (COVID-19) has caused almost 2.9 million deaths, and the numbers continue to increase [1]. The therapeutic options remain limited. Few studies have reported improved clinical outcomes in hospitalized COVID-19 patients with use of famotidine [2, 3]. A case series demonstrated improved outpatient outcomes with use of high-dose famotidine [4]. Another observational study showed that combination of antihistamines including famotidine and cetirizine improved the mortality and symptom progression [5]. A recent large multicentre observational study did not show any mortality benefit with use of famotidine [6]. A recent meta-analysis by Kamal et al. showed that conclusions regarding the safety and effectiveness of PPI and famotidine cannot be drawn based on conflicting and heterogeneous data [7]. Great enthusiasm can be observed regarding the use of famotidine or $\mathrm{H}_{2}$ receptor blockers, and sometimes these agents are preferred over proton pump inhibitors (PPI), which are more affective agents for upper gastrointestinal symptoms [8]. The activation of mast cells and pathological release of histamine in the setting of COVID-19 infection leads to severe inflammation. It is thought that $\mathrm{H}_{2}$ receptor antagonist $\left(\mathrm{H}_{2} \mathrm{RA}\right)$ may attenuate this effect [9]. 
Also famotidine is a potential inhibitor of 3-chymotrypsin-like protease (3CLpro), which is involved in the virus replication [10]. The commonly used famotidine formulation (Pepcid Complete) contains calcium, and hypocalcaemia is commonly seen in severe COVID-19 infection. The calcium can interact with fats and impede the lipotoxicity and as a result improve outcomes [11]. Most of the available studies utilized the medication data obtained during hospitalization. The literature regarding the impact of $\mathrm{H}_{2}$ receptor blocker for long-term use or as home medication is scarce [12].

\section{Aim}

We aim to study $\mathrm{H}_{2}$ receptor antagonist $\left(\mathrm{H}_{2} \mathrm{RA}\right)$ use in hospitalized patients and its impact on the mortality and hospital-related outcomes. We also compared the outcomes in patients on $\mathrm{H}_{2}$ RA with patients using PPI.

\section{Material and methods \\ Study population}

This retrospective cohort study was conducted at a tertiary care hospital in Albany, located in upstate New York, which has large catchment area. After a chart review, we identified all hospitalized patients diagnosed with COVID-19 infection between 1 March 2020 and 31 July 2020. The study was approved by the institutional review board of Albany Medical Centre with patient consent waived.

After chart review, we included patients above 18 years old who were diagnosed with COVID-19. Patients were excluded if they were older than 90 years. The cases with incomplete data were excluded. The baseline date was chosen from the date of hospital admission.

\section{Baseline data and covariates}

COVID-19 was diagnosed by nasopharyngeal polymerase chain reaction. Severe COVID-19 infection was defined as $\mathrm{SpO}_{2}<94 \%$ in room air, ratio of partial pressure of oxygen and inspired air fraction $\left(\mathrm{PaO}_{2} / \mathrm{FiO}_{2}\right)$ $<300 \mathrm{~mm} \mathrm{Hg}$, more than 50\% involvement of lungs, and respiratory rate $>30$ breaths $/ \mathrm{min}$. Patients with critical illness, who had multiorgan failure were also considered as severe COVID-19 [13]. Chronic kidney disease (CKD) was defined as GFR $<60 \mathrm{ml} / \mathrm{min} / 1.73 \mathrm{~m}^{2}$ measured on 2 separate occasions [14].

Baseline demographic data including age, sex, race, and comorbidities including obesity, hypertension, coronary artery disease (CAD), chronic obstructive pulmonary disease (COPD), history of cancer, liver disease, immunodeficiency, and cigarette smoking were extracted after a careful chart review. Medication use including $\mathrm{PPI}$ and $\mathrm{H}_{2}$ RA were recorded from the medication histo- ry at time of the diagnosis or most recent prescription record before the hospital admission.

The study subjects were segregated into $\mathrm{H}_{2} \mathrm{RA}$ users and non-users. The patients on PPI were also compared with patients on $\mathrm{H}_{2} \mathrm{RA}$.

\section{Outcomes}

The primary outcome was the mortality in the groups of $\mathrm{H}_{2}$ RA users, $\mathrm{H}_{2}$ RA non-users, and PPI users. The secondary outcomes included development of severe COVID-19 infection with acute respiratory distress syndrome (ARDS) and thromboembolism requiring ICU admission and mechanical ventilation. We also recorded the length of admission and the readmission in all groups.

\section{Statistical analysis}

The baseline characteristics were presented as percentages for the categorical variables and mean \pm SD for continuous variables and were compared between $\mathrm{H}_{2} \mathrm{RA}$ users and non-users. A multivariate logistic regression model was used to assess the association between $\mathrm{H}_{2} \mathrm{RA}$ use and other covariates with mortality during the study period. These models were adjusted for age, sex, race, diabetes, CAD, COPD, asthma, history of cancer, chronic kidney disease, liver disease, obesity, and cigarette smoking. We also evaluated the same predictors among $\mathrm{H}_{2} \mathrm{RA}$ and PPI subgroups. All analyses were conducted using STATA 16. A $p$-value $<0.05$ was considered significant.

\section{Results}

\section{Demographics}

During the study period 407 adult patients were admitted from March till July 2020 with COVID-19 infection. Of those, 11 patients had incomplete data. Of the remaining 396 patients, 86 received PPI, 39 received $\mathrm{H}_{2} \mathrm{RA}$, and 6 patients received both PPI and $\mathrm{H}_{2} \mathrm{RA}$. Among $\mathrm{H}_{2} \mathrm{RA}$ users, 33 were taking famotidine, 5 were on ranitidine, and 1 was taking cimetidine. These 6 patients were excluded while comparing $\mathrm{H}_{2} \mathrm{RA}$ and PPI (Figure 1).

The demographics were similar for $\mathrm{H}_{2} \mathrm{RA}$ users and non-users. The mean age was $57.79 \pm 17.36$ years, $43.2 \%$ were female, and $48.7 \%$ were Caucasian. The most common secondary diagnoses were hypertension (56.8\%), obesity (44.4\%), diabetes mellitus (38.6\%), coronary artery disease (30.1\%), chronic kidney disease (19.2\%), asthma (15.2\%), and chronic obstructive pulmonary disease (13.6\%). As compared to $\mathrm{H}_{2}$ RA non-users, the $\mathrm{H}_{2} \mathrm{RA}$ user group had higher percentages of CAD (19.6\% vs. $38.5 \%, p=0.006)$, asthma ( $13.7 \%$ vs. $28.2 \%$, 


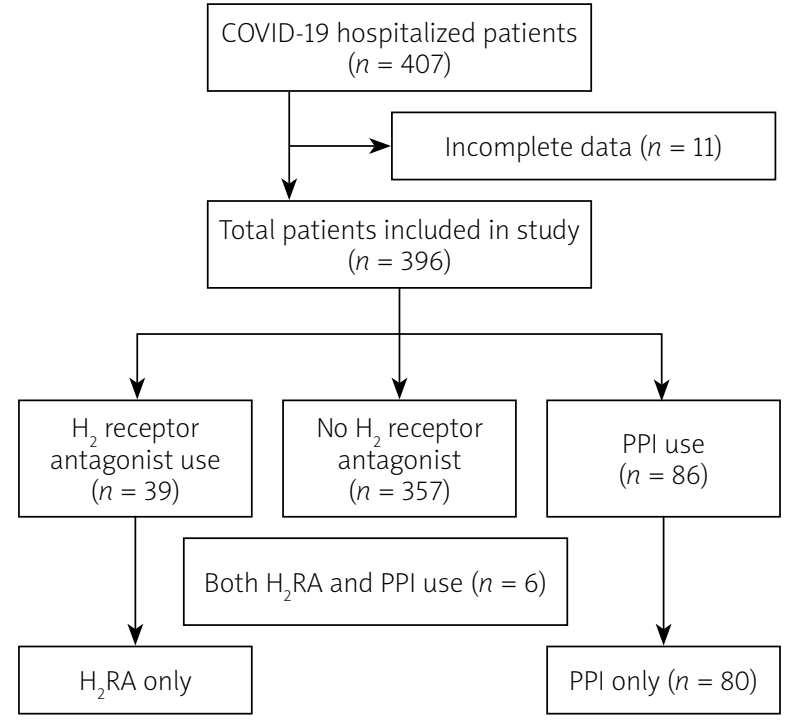

Figure 1. Flowchart showing the coronavirus disease 19 patient population

$\mathrm{H}_{2} \mathrm{RA}-\mathrm{H}_{2}$ receptor antagonist, $\mathrm{PPI}$ - proton pump inhibitor. $p=0.02$ ), and hypertension (55.2\% vs. $71.8 \%, p=0.05$ ). The patients taking PPI had similar demographics and covariates as compared to $\mathrm{H}_{2} \mathrm{RA}$ users. The past and present cigarette smoking was more prevalent in patients taking PPI (42.5\% vs. $18.2 \%, p=0.03)$. Gastrointestinal symptoms were seen in $31.1 \%$, and $43.9 \%$ of patients had abnormal liver enzymes on initial presentation (Table I).

\section{Mortality and adverse outcomes}

The study period was $6.3 \pm 2.9$ months. During this period 71 patients died -8 (20.5\%) were taking $\mathrm{H}_{2} \mathrm{RA}$. There was no significant difference in mortality between $\mathrm{H}_{2} \mathrm{RA}$ users and non-users $(\mathrm{HR}=0.84,95 \% \mathrm{Cl}$ : $0.35-2.05)$ and the PPI group ( $\mathrm{HR}=0.34-3.19,95 \% \mathrm{Cl}$ : 0.34-3.19). The use of $\mathrm{H}_{2} \mathrm{R}$ did not impact the readmission $(\mathrm{HR}=1.43,95 \% \mathrm{Cl}$ : 0.66-3.11) (Figures 2, 3).

The length of stay was modestly longer in the $\mathrm{H}_{2} \mathrm{RA}$ user group as compared to the non-user group (16.08 \pm 15.04 days vs. $11.4 \pm 12.1$ days, $p=0.05)$. The $\mathrm{H}_{2} \mathrm{RA}$

Table I. Baseline characteristics of COVID-19 patients taking either proton pump inhibitor or histamine $\mathrm{H}_{2}$ receptor antagonist

\begin{tabular}{|c|c|c|c|c|c|c|c|}
\hline Variables & $\begin{array}{l}\text { Total patients } \\
\quad(n=396)\end{array}$ & $\begin{array}{c}\mathrm{H}_{2} \text { receptor } \\
\text { blocker } \\
(n=39)\end{array}$ & $\begin{array}{l}\mathrm{No}_{2} \\
\text { receptor } \\
\text { blocker } \\
(n=357)\end{array}$ & $P$-value & $\begin{array}{c}\mathrm{H}_{2} \text { receptor } \\
\text { blocker } \\
(n=33)\end{array}$ & $\begin{array}{c}\text { PPI } \\
(n=80)\end{array}$ & $P$-value \\
\hline Age & $57.79 \pm 17.36$ & $62.67 \pm 17.01$ & $57.25 \pm 17.33$ & 0.06 & $61.25 \pm 16.39$ & $62.66 \pm 15.11$ & 0.60 \\
\hline Female & $171(43.2)$ & $18(46.2)$ & $154(42.9)$ & 0.69 & $14(42.4)$ & $32(40)$ & 0.81 \\
\hline White & 193 (48.7) & $23(59 \%)$ & $170(47.6)$ & 0.36 & $65(60.6)$ & $45(56.3)$ & 0.95 \\
\hline BMI & $30.97 \pm 8.43$ & $30.97 \pm 9.05$ & $30.97 \pm 8.37$ & 0.99 & & & \\
\hline CAD & $21.5(30.1)$ & $15(38.5)$ & 70 (19.6) & 0.006 & $12(36.4)$ & $22(27.5)$ & 0.35 \\
\hline COPD & $54(13.6)$ & 7 (17.9) & 47 (13.2) & 0.41 & $6(18.2)$ & $16(20)$ & 0.82 \\
\hline Asthma & $60(15.2)$ & $11(28.2)$ & 49 (13.7) & 0.02 & $9(27.3)$ & $16(20)$ & 0.40 \\
\hline Cancer & $32(8.1)$ & $4(10.3)$ & $28(7.8)$ & 0.6 & $2(6.1)$ & $10(12.5)$ & 0.31 \\
\hline CKD & $76(19.2)$ & $5(12.8)$ & 71 (19.9) & 0.28 & $5(15.2)$ & $20(25)$ & 0.25 \\
\hline DM & $153(38.6)$ & $19(48.7)$ & $134(37.5)$ & 0.17 & $16(48.5)$ & $38(47.5)$ & 0.92 \\
\hline HTN & $225(56.8)$ & $28(71.8)$ & $197(55.2)$ & 0.05 & $23(69.7)$ & $53(66.3)$ & 0.72 \\
\hline Immunodeficiency & $20(5.1)$ & $3(7.7)$ & $17(4.8)$ & 0.43 & $2(6.1)$ & $6(7.5)$ & 0.79 \\
\hline Liver disease & 47 (11.7) & $4(10.3)$ & $43(12)$ & 0.86 & $2(6.1)$ & $14(17.5)$ & 0.15 \\
\hline Obesity & $176(44.4)$ & $18(46.2)$ & $158(44.3)$ & 0.82 & $15(45.5)$ & $39(48.8)$ & 0.75 \\
\hline Smoking & $131(33.1)$ & $8(20.5)$ & $123(34.5)$ & 0.09 & $6(18.2)$ & $34(42.5)$ & 0.03 \\
\hline Gl symptoms & $123(31.1)$ & $11(28.2)$ & 112 (31.4) & 0.69 & $9(27.3)$ & $23(28.8)$ & 0.87 \\
\hline Elevated LFT & 174 (43.9) & 19 (48.7) & 155 (43.4) & 0.76 & $15(45.5)$ & $36(45)$ & 0.86 \\
\hline LFT 3 UNL & $24(6.1)$ & $1(2.6)$ & $23(6.4)$ & 0.30 & $1(3.0)$ & $5(6.3)$ & 0.51 \\
\hline
\end{tabular}

PPI - proton pump inhibitor, BMI - body mass index, CAD - coronary artery disease, COPD - chronic obstructive pulmonary disease, CKD - chronic kidney disease, DM - diabetes mellitus, HTN - hypertension, GI - gastrointestinal, LFT - liver function tests, UNL - upper normal limit. 


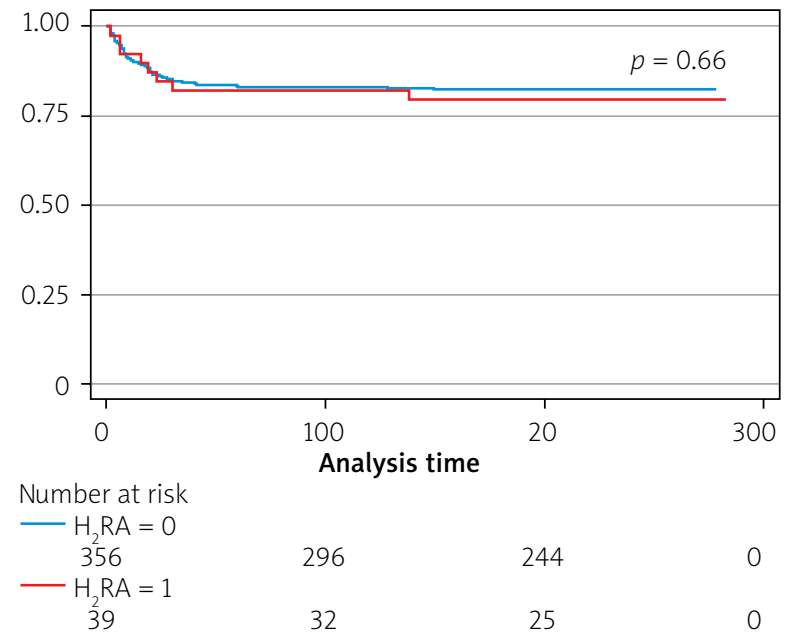

Figure 2. Kaplan Meier survival by use of $\mathrm{H}_{2}$ receptor antagonist and no $\mathrm{H}_{2}$ receptor antagonist

user group had similar length of stay as compared to the PPI group. The rest of the outcomes including thromboembolism, acute respiratory distress syndrome, severe COVID-19 infection, and level of care including ventilation and ICU stay were similar in the $\mathrm{H}_{2} \mathrm{RA}$ user group compared to $\mathrm{H}_{2} \mathrm{RA}$ non-user and PPI group (Tables II and III).

\section{Discussion}

Our retrospective study has demonstrated that the use of $\mathrm{H}_{2}$ RA had no influence on mortality when compared to patients not on $\mathrm{H}_{2} \mathrm{RA}$ and those using PPI. The use of $\mathrm{H}_{2} \mathrm{RA}$ as a home medication was associated with modestly increased length of stay, but it had no impact on readmission rate, severity of COVID-19 infection, level of care, and thromboembolism.

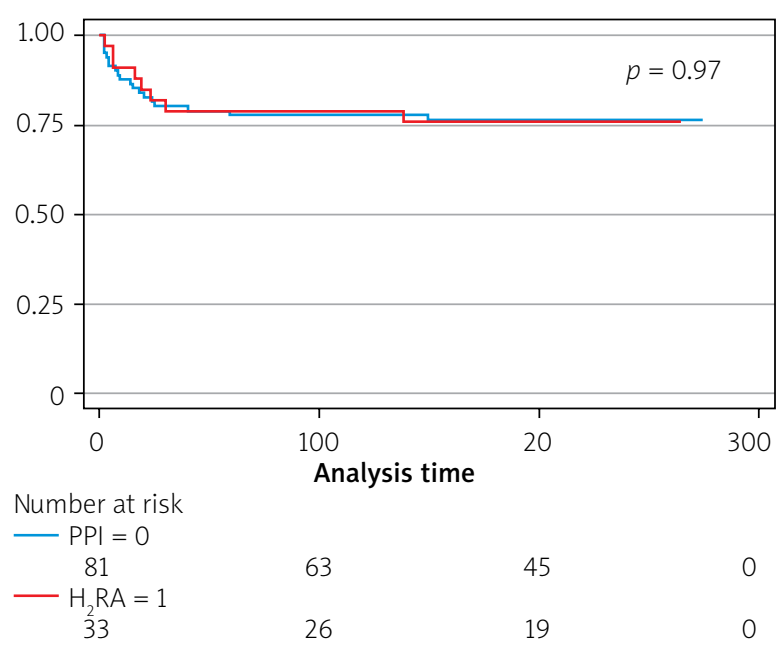

Figure 3. Kaplan Meier survival curve by use of $\mathrm{H}_{2}$ receptor antagonist and proton pump inhibitor $\mathrm{H}_{2} \mathrm{RA}-\mathrm{H}_{2}$ receptor antagonist, $\mathrm{PPI}$ - proton pump inhibitor.

Previous studies proposed that famotidine reduces the inflammation in response to SARS-CoV-2 [3]. The improved outcomes with use of famotidine in previous studies are making PPI a less attractive option for clinicians. We believe that there was selection bias that confounded the results in previous positive studies. The subjects who received famotidine were less sick and as a result had better outcomes. We were unable to produce the same result when we took patients with $\mathrm{H}_{2} \mathrm{RA}$ as a home medication into consideration.

Theoretically, the low acid levels that occur in the stomach with the use of $\mathrm{H}_{2} \mathrm{RA}$ and PPI can lower the defence against viral infections [15]. However, it is unknown if this mechanism can cause poor outcomes in COVID-19 patients. A recent study by Yeramaneni et al.

Table II. Independent association of the $\mathrm{H}_{2}$ blocker use compared to non $\mathrm{H}_{2}$ blocker with outcomes

\begin{tabular}{lccccc} 
& \multicolumn{1}{c}{$\mathrm{H}_{2}$ receptor blocker } & & Hazard ratio & 95\% Cl \\
\cline { 2 - 4 } & Present & Absent & & \\
\hline Mortality & $8(20.5)$ & $63(17.6)$ & 0.84 & $0.35-2.05$ & 0.71 \\
\hline Readmission & $9(23.1)$ & $56(15.7)$ & 1.43 & $0.66-3.11$
\end{tabular}

\begin{tabular}{|c|c|c|c|c|c|}
\hline \multicolumn{6}{|c|}{ Adjusted odds ratio } \\
\hline Thromboembolism & $25(7)$ & $3(7.7)$ & 0.84 & $0.17-4.02$ & 0.83 \\
\hline ARDS & $14(35.9)$ & $82(23)$ & 1.73 & $0.76-4.0$ & 0.19 \\
\hline Severe COVID-19 & $18(46.2)$ & $127(35.6)$ & 1.14 & $0.52-2.47$ & 0.74 \\
\hline ICU admission & $16(41)$ & $113(31.7)$ & 1.3 & $0.6-2.84$ & 0.50 \\
\hline Ventilated & $9(23.1)$ & $73(20.4)$ & 1.25 & $0.51-3.06$ & 0.63 \\
\hline LOS & $16.08 \pm 15.04$ & $11.4 \pm 12.1$ & 4.17 & $0.07-8.4$ & 0.05 \\
\hline
\end{tabular}

ARDS - acute respiratory distress syndrome, COVID-19 - corona virus disease 2019, ICU - intensive care unit, LOS - length of stay. 
Table III. Independent association of the $\mathrm{H}_{2}$ blocker use compared to proton pump inhibitors with outcomes

\begin{tabular}{lccccc}
\hline Outcomes & $\mathbf{H}_{\mathbf{2}}$ blocker use $(n=\mathbf{3 3})$ & PPI $(\boldsymbol{n}=\mathbf{8 0})$ & Adjusted odds ratio & $\mathbf{9 5 \%} \mathrm{Cl}$ & $\boldsymbol{P}$-value \\
\hline Mortality & $8(24.2)$ & $19(23.8)$ & 1.04 & $0.34-3.19$ & 0.94 \\
\hline Readmission & $8(24.2)$ & $16(20)$ & 1.52 & $0.46-4.15$ & 0.42
\end{tabular}

\begin{tabular}{lccccc} 
Thromboembolism & $3(9.1)$ & $5(6.3)$ & 8.13 & $0.36-182.4$ & 0.19 \\
\hline ARDS & $13(39.4)$ & $17(21.3)$ & 2.74 & $0.79-9.51$ & 0.11 \\
\hline Severe COVID-19 & $17(51.5)$ & $35(43.8)$ & 1.57 & $0.51-4.82$ & 0.43 \\
\hline ICU admission & $15(45.5)$ & $26(32.5)$ & 2.34 & $0.81-6.75$ & 0.12 \\
\hline Ventilated & $9(27.3)$ & $17(21.3)$ & 2.31 & $0.67-7.97$ & 0.18 \\
\hline LOS & $15.56 \pm 14.49$ & $13.26 \pm 14.1$ & 0.82 & $-5.49-7.12$ & 0.8
\end{tabular}

ARDS - acute respiratory distress syndrome, COVID-19 - corona virus disease 2019, ICU - intensive care unit, LOS - length of stay.

[6] showed that the inpatient famotidine use in patients who were not taking this medicine at home was associated with higher 30-day mortality.

The strengths of our study are the diversity of the patient population, granularity in obtaining patient characteristics, and complete follow-up for the duration of the study period. We included patients based on $\mathrm{H}_{2} \mathrm{RA}$ or PPI as home medications, unlike published studies in which the medications were used only during the hospitalization. The risk of selection bias is minimal. Our study also has several limitations, including the retrospective study design and single-centre setting. The adjudication we tried to limit by using 2 reviewers independently collecting information from the medical records. ICD 9 and ICD 10 codes were used to identify the patients. It is possible that some patients might have been misclassified. Careful chart auditing was performed to limit the misdiagnosis. Both PPI and $\mathrm{H}_{2} \mathrm{RA}$ are utilized as over-the-counter medications, and underestimation is possible. There is variability in dosing of these medications, although the majority our patients were using a modest single daily dose.

\section{Conclusions}

The use of $\mathrm{H}_{2} \mathrm{RA}$ is not associated with improved outcomes in COVID-19 hospitalized patients, nor did it show any advantage over PPI. The clinical outcomes with use of $\mathrm{H}_{2}$ RA in COVID-19 patients are inconsistent, and the management of peptic ulcer disease or stress ulcer prophylaxis management should remain unchanged during the COVID-19 pandemic. Prospective studies are required to better understand any role of acid suppressant medications in COVID-19 patients.

\section{Conflict of interest}

The authors declare no conflict of interest.

\section{References}

1. World Health Organization. Coronavirus disease (COVID-19) pandemic. Published online 2021. https://www.who.int/emergencies/diseases/novel-coronavirus-2019

2. Mather JF, Seip RL, McKay RG. Impact of famotidine use on clinical outcomes of hospitalized patients with COVID-19. J Am Coll Gastroenterol 2020; 115: 1617-23.

3. Freedberg DE, Conigliaro J, Wang TC, et al. Famotidine use is associated with improved clinical outcomes in hospitalized COVID-19 patients: a propensity score matched retrospective cohort study. Gastroenterology 2020; 159: 1129-31.

4. Janowitz T, Gablenz E, Pattinson D, et al. Famotidine use and quantitative symptom tracking for COVID-19 in non-hospitalised patients: a case series. Gut 2020; 69: 1592-7.

5. Hogan li RB, Hogan lii RB, Cannon T, et al. Dual-histamine receptor blockade with cetirizine - famotidine reduces pulmonary symptoms in COVID-19 patients. Pulm Pharmacol Ther 2020; 63: 101942.

6. Yeramaneni S, Doshi P, Sands K, et al. Famotidine use is not associated with 30-day mortality: a coarsened exact match study in 7158 hospitalized patients with coronavirus disease 2019 from a large healthcare system. Gastroenterology 2021; 160: 919-21.

7. Kamal F, Khan MA, Sharma S, et al. Lack of consistent associations between pharmacological gastric acid suppression and adverse outcomes in patients with COVID-19: meta-analysis of observational studies. Gastroenterology 2021; 160: 2588-90.

8. Fujiwara Y, Higuchi K, Nebiki H, et al. Famotidine vs. omeprazole: a prospective randomized multicentre trial to determine efficacy in non-erosive gastro-oesophageal reflux disease. Aliment Pharmacol Ther 2005; 21 Suppl 2: 10-8.

9. Malone RW, Tisdall P, Fremont-Smith P, et al. COVID-19: famotidine, histamine, mast cells, and mechanisms. Res Sq 2020. doi:10.21203/rs.3.rs-30934/v2.

10. Wu C, Liu Y, Yang Y, et al. Analysis of therapeutic targets for SARS-CoV- 2 and discovery of potential drugs by computational methods. Acta Pharm Sin B 2020; 10: 766-88.

11. El-Kurdi B, Khatua B, Rood C, et al. Mortality from coronavirus disease 2019 increases with unsaturated fat and may be re- 
duced by early calcium and albumin supplementation. Gastroenterology 2020; 159: 1015-8.

12. Amjad W, Malik A. Famotidine and hospitalized COVID-19 patients: are the benefits true? J Am Coll Gastroenterol 2021 doi: 10.14309/ajg.0000000000001217.

13. NIH. Coronavirus Disease 2019 (COVID-19) Treatment Guidelines. Disponible en: https://covid19treatmentguidelines.nih. gov/. Nih. 2020; 2019: 130.

14. Levey AS, Stevens LA, Schmid CH, et al. A new equation to estimate glomerular filtration rate. Ann Intern Med 2009; 150: 604-12.

15. Martinsen TC, Bergh K, Waldum HL. Gastric juice: a barrier against infectious diseases. Basic Clin Pharmacol Toxicol 2005; 96: 94-102.

Received: 12.04 .2021

Accepted: 1.06.2021 